\title{
Performance study on the CI engine using LHR and LTC in combination with biodiesel blends
}

\author{
RT Sarathbabu* and M Kannan** \\ * Mechanical Engineering, Mother Theresa Institute of Engineering and Technology, Palamaner, India. \\ ** Mechanical Engineering, KCG College of Technology, Chennai, India. \\ * Corresponding Author: saratht1983@gmail.com
}

Submitted :09/05/2020

Revised : 29/03/2021

Accepted :28/05/2021

\begin{abstract}
Currently, the research of a single-cylinder 4-stroke direct injection diesel engine, which was naturally aspired, was used, and two modification methods were used. The first is the low-heat rejection method (LHR), and the second is the low-temperature combustion method (LTC). LHR was introduced into the engine by ceramic coating with alumina, which is applied to engine components such as the piston, cylinder lining, and valves, and it has a thickness of 300 microns without affecting the dimensions of the engine parts. In the next method, low-temperature combustion (LTC) method is done with EGR technique. And the exhaust gas recirculation setting (EGR) is included in the same setup as that of the first method. Since $15 \%$ of the exhaust gas is used in the EGR process, the diesel is blended with $20 \%$ of mahua biodiesel and $5 \%$ of ethanol as a fuel. After that, the engine performance is tested with conventional fuel when compared with biodiesel as a combined LHR and LTC methods. Finally, the engine output is increased by up to $3.48 \%$ as a result of the combination of LHR and LTC. As a result, emission levels could be dramatically decreased, and other results obtained could include a decrease in infrared radiation, resulting in a decrease in specific fuel consumption (SFC), and a substantial improvement in engine efficiency characteristics.
\end{abstract}

Keywords: Low heat rejection; Low-temperature combustion; Mahua biodiesel; Alumina; Ethanol.

\section{INTRODUCTION}

The diesel engine, also known as the compression ignition engine or CI engine, is an internal combustion engine, in which the ignition of the fuel injected into the combustion chamber is initiated by the high temperature achieved by a gas when it is heavily compressed by adiabatic compression. This contrasts with spark-ignition engines, like a petrol engine, which uses a spark plug to ignite a mixture of air-fuel. Because of its compression and low combustion ratio, the diesel engine has a better thermal efficiency than all internal or external combustion engines, allowing excess air to dissipate heat (Heywood JB, 2002). Diesel engines are produced in the versions of two and four strokes. Nowadays, the two-stroke engines are banned in cars but used in marine applications, because the pollutants from the two-stroke engines are very high compared to the four-stroke engines (Muthukumaran et al., 2018). In two-stroke engines, the power stroke is obtained by each crank revolution, so that we get the power output twice as much as the four-stroke. Due to higher combustion temperatures, $\mathrm{NO}_{\mathrm{x}}$, particulate matter, and smoke emissions are high in diesel 
engines. The combustion of diesel engines depends primarily on the compression pressure and the automatic ignition temperature of the fuel. In all fields such as agriculture, industry, power generation, and automobiles, the diesel engine plays a vital role. By taking human health into account, researchers are testing new techniques for reducing NOx, smoke, and hydrocarbon emissions from the engine (Rakopoulos et al., 2006). By making certain changes, such as exhaust gas recirculation, increasing the injection pressure and retarding or advancing the injection timing, emissions and fuel economy are reduced. Although diesel engines have high thermal efficiency and high torque capacity and produce fewer HC and $\mathrm{CO}$ emissions than gasoline engines, they emit NOx and smoke (Kulkarni et al., 2011 \& Vamsi Krishna et al. 2018), which pose a major threat to the clean environment and human health. The automotive industry has grown rapidly, especially in IC engine invention and implementation. Thus, the use of IC engines has grown considerably throughout the world. In this experiment, four different conditions (Diesel, B20, B20 (LHR), and B20E5 (LHR+15\%LTC)) of diesel engine are investigated and compared with conventional engine.

\section{LITERATURE REVIEW}

Kannan and Anand (2011) have investigated the diesel engine efficiency, combustion, and emission characteristics run by diesel-biodiesel-ethanol blends or diestrol fuels. Based on the calorific value, miscibility and stability of blends are tested at temperatures of $40^{\circ} \mathrm{C}$ to $10^{\circ} \mathrm{C}$, and eleven combinations of fuel blends are selected. The engine operated at a constant speed of $1500 \mathrm{rpm}$ with selected fuels. Finally, the authors concluded from the experimental results that high brake thermal efficiency $29.9 \%$ is obtained in diestrol (B30D60E10) fuel. Heat release of diesel is $7.5 \%$ higher than diestrol fuel under full load conditions. In biodiesel ignition delay $1.9^{\circ} \mathrm{CA}$ higher than diesel. By using B30D60E10 diestrol fuel, NO and smoke emissions decreased compared to diesel. They have proven that B30D60E10 is the best alternative diesel fuel without modification compared to other biodiesel combination blends.

Xue et al. (2011) studies have reviewed the number of highly cited science index journals on biodiesel engine performance, combustion, and emission characteristics. The review of journals focused on the biodiesel engine effects of brake power, efficiency, and emissions. The authors concluded that the use of biodiesel rather than diesel reduces $\mathrm{CO}, \mathrm{HC}$, and PM emissions from studies. Fuel consumption and NOx emissions, however, increase without any modification of the diesel engine. If engine modification and some additives are added to biodiesel to optimize performance and completely alternate diesel fuel.

Muthukumaran et al. (2018) prepared mahua biodiesel using a catalytic cracking process and investigated diesel engine performance, combustion, and emission characteristics fueled by cracked mahua biodiesel blend with diesel. Mahua biodiesel has been produced by using cheap heterogeneous catalysts (coal ash) because of the reduction in biofuel costs. The authors have identified that cracked mahua biofuels are better analyzed with FTIR, GC spectrum. Coal ash compositions such as silicon, oxygen, aluminum, and iron levels are analyzed using SEM and EDC for the cracking process. Mahua biodiesel is blend with diesel such as B25, B50, B75, and B100 at different load conditions.

Finally, the authors conclude that B25 brake thermal efficiency is close to pure diesel, and $\mathrm{B} 100 \mathrm{NO}_{\mathrm{x}}$ emissions are $3.2 \%$ lower than those of diesel at $20 \%$ load conditions. With increases in the percentage of biodiesel blends for all load conditions, $\mathrm{HC}$ and $\mathrm{CO}$ emissions were increased. The maximum heat release was obtained in $\mathrm{B} 25$ compared to other blends.

Masjuki et al. (1996) studied viscosity reduction of palm oil methyl esters (POME) by using a 100oC preheating temperature in diesel engines. They examined preheated biodiesel fuel in diesel engine performance, combustion, and emission characteristics. From the results, the authors concluded that the brake power output of biofuel is closer to diesel fuel operations. Preheated air intake temperatures of $60^{\circ} \mathrm{C}$ have reduced $\mathrm{HC}$ emissions reasonably well. 
Engine air intake temperatures have been used to stabilize fuel to improve efficiency and emissions compared to diesel fuel.

Kulkarni et al. (2011) have investigated the performance of diesel engines using a low-heat rejection method fueled by mahua oil methyl ester (MOME) before and after exhaust gas recirculation (EGR) ratios of $0 \%$ to $20 \%$. In this study, the following engine parameters are kept constant, that is, speed $1500 \mathrm{rpm}$, injection time $23^{\circ} \mathrm{BTDC}$, compression ratio 17.5, and injection pressure 204 bar for diesel and 240 bar for MOME. The ceramic coating is used to implement low heat rejection in the engine by using YSZ (yttria-stabilized zirconia) in engine parts with a thickness of $200 \mu \mathrm{m}$, such as piston, cylinder head, and valves. EGR ratios were varied using controlling valves. The authors have observed that LHR engine increases the brake thermal efficiency, reduces the emissions like $\mathrm{HC}$ and $\mathrm{CO}$, and increases the $\mathrm{NO}_{\mathrm{x}}$ compared to conventional engine fuelled by MOME. When the EGR rate increases, BTE also increases and slightly increases the emissions including $\mathrm{HC}$ and $\mathrm{CO}$ and decreases the $\mathrm{NO}_{\mathrm{x}}$. Finally, the authors concluded that, at 10\%, EGR has reduced $\mathrm{NO}_{\mathrm{x}}$ and improved the engine overall performance.

Vamsi Krishna et al. (2018) investigated performance, emissions, and cylinder pressure by using the semiadiabatic diesel engine (SADE) combined with the EGR rate 10-percent diesel fuel and A15B85 blend by vol. (Additive Diethyl Ether 15\% + Biodiesel 85\% rubber seed) compared with the ordinary diesel engine (ODE). SADE has been produced by using a ceramic coated cylinder head with a thickness of $400 \mu \mathrm{m}$ thermal barrier $8 \mathrm{YSZ}$ and an intermediate layer made by using $\mathrm{NiCrAl}$ bond coat with a thickness of $100 \mu \mathrm{m}$ without change dimensions. In this experimental work, the authors maintained a constant engine speed at $1800 \mathrm{rpm}$, a compression ratio of 18.1, and an injection pressure of 190 bar with varying load conditions of 0 to $100 \%$ and a varied start of injections from 30 to $35^{\circ}$ BTDC. The results showed that SADE's 7\% improvement in BTE reduces fuel consumption by $5.5 \%$ compared to ordinary diesel engines. And engine emissions like $\mathrm{NO}_{\mathrm{x}}$ and particulate matter (PM) decreased by $19.5 \%$ and 48.5 $\%$, with $33^{\circ} \mathrm{BTDC}$ at full fuel blend load. Finally, the authors concluded that the A15B85 blend by volume has proven to be $100 \%$ renewable fuel for the diesel engine, and $10 \%$ EGR is optimal to reduce $\mathrm{NO}_{\mathrm{x}}$ emissions with combined thermal engine barriers.

Geos et al. (2017) investigated the enhancement of diesel engine combustion by injecting ethanol during suction stroke intake. Engine fuel is such as diesel, rubber seed oil (RSO), and rubber seed oil methyl ester (RSOME). In this study, the authors interest is to use alcohol in the compression ignition engine as an alternative biofuel due to oxygen, and it is prepared by using biomass. In this research, optimized injection timing and duration used dual fuel operation of ethanol injection. The authors compared the results of engine performance with various fuel mixtures with different ethanol energy ratios of $0 \%$ to $45 \%$. The results of the experiment illustrate that the brake thermal efficiency rises with the rise in the ethanol energy ratios of all fuels due to premix combustion rates. However, it increases $\mathrm{NO}_{\mathrm{x}}$ emissions due to higher oxygen content under full load conditions. Smoke levels also decreased at maximum brake thermal efficiency for all tested ethanol injection fuels. $\mathrm{HC}$ and $\mathrm{CO}$ emission levels increase due to ethanol injection of all fuels. Combustion duration and ignition delay are higher in RSO compared to diesel due to ethanol injection. Finally, the authors concluded that there is an improvement of thermal efficiency and reduced smoke levels in the diesel engine with ethanol injection powered by diesel, rubber seed oil, and its ester at all loads.

Ramalingam et al. (2018) have reviewed the number of research articles on biodiesel-fuelled diesel engines to reduce the disadvantages of fossil fuels. The authors from their studies focus on biodiesel as an alternative fuel to the replacement of fossil fuel for diesel engines. They examined the methods and technologies used to improve efficiencies and reduce emissions of biodiesel fuelled by diesel engines. Finally, they concluded that, due to the low heating value of biofuels, biodiesel reduced the brake thermal efficiency compared to diesel. However, it reduces the engine exhaust emissions like $\mathrm{CO}, \mathrm{UHC}$, and smoke owing to the oxygen content of biofuels and increases $\mathrm{NO}_{\mathrm{x}}$ emissions. This type of disadvantage has been rectified by increasing the engine compression ratio and some minor modifications needed to increase efficiency. B20 is the best combination of biodiesel used for alternative diesel fuel 
in the compression ignition engine with the catalytic converter and increases the compression ratios with minor modifications in the engine.

Govinda Rao et al. (2018) conducted a study of diesel engine performance and emission characteristics of diesel fuel, waste plastic oil, and its mixtures by varying injection parameters and compression ratios. In this study, the authors have used different ratios of diesel, ethanol-blended with plastic oil for test fuels. From experimental results, blend P90D5E5 has maximum thermal efficiency and reduced fuel consumption, carbon monoxide, and smoke levels compared to pure diesel and pure plastic oil. And it has a high heat release rate and cylinder pressure. Finally, the authors conclude that increasing the compression ratio, injection pressure, and retarding injection leads to increased engine efficiency and $\mathrm{NO}_{\mathrm{x}}$ but decreases emissions of $\mathrm{CO}, \mathrm{HC}$, smoke, and also specific fuel consumption.

Modi et al. (2017) have investigated the performance of the twin-cylinder diesel engine by using ceramic coated engine parts with different EGR ratios fueled by diesel and neem biodiesel blends. The authors focused on reducing engine heat rejection and improving energy conservation and efficiency following the second law of thermodynamics. Ceramic is coated on the engine piston and top surface of the cylinder head with partially stabilized zirconia (PSZ) thermal barrier material. The effect of the thermal barrier in the engine increases thermal efficiency and reduces exhaust emissions such as $\mathrm{HC}, \mathrm{CO}$, and smoke but increases $\mathrm{NO}_{\mathrm{x}}$. And after implementing the EGR in the engine, it reduces $\mathrm{NO}_{\mathrm{x}}$ and increases thermal efficiency by lowering a combustion temperature and the amount of oxygen content in the engine cylinder. The entire experimental work engine is operated at a constant speed of 2000 rpm. From the results, the EGR 5 percent with the LHR engine reduces both $\mathrm{NO}_{\mathrm{x}}$ and smoke density by $26 \%$ and 15\%. EGR $10 \%$ with the LHR engine reduces both $\mathrm{NO}_{\mathrm{x}}$ and smoke by $34 \%$ and $30 \%$.

Senthil et al. (2015) examined and compared the performance and emission characteristics of single-cylinder diesel engines fueled by Nerium oil diesel and methyl ester before and after the coating of ceramic materials. Engine parts such as the surface of the top of the cylinder head, piston, and valves are coated with partially stabilized zirconia (PSZ) by using plasma spray coating. The results of the experiment showed that the specific fuel consumption was reduced in all load conditions in the coated engine. Finally, the author identifies the thermal efficiency of the coated engine brake around 3.8 percent higher than the uncoated engine. And coated engine emissions improved than the uncoated engine, except $\mathrm{NO}_{\mathrm{x}}$.

Banapurmath and Tewari (2009) investigated the improvement in a diesel engine efficiency with a low heat rejection (LHR), and exhaust gas recirculation (EGR) fueled by diesel, hinge and neem oil methyl ester. In this experiment, the alternative fuel for diesel engines with varying injection times of 19,23 , and $27^{\circ} \mathrm{BTDC}$ with and without EGR ratios of $5 \%$ to $20 \%$ was examined. The results improved the specific fuel consumption and brake thermal efficiency of the LHR biodiesel engine. However, $10 \%$ of EGR with the LHR engine has better performance and reduced emissions such as $\mathrm{HC}, \mathrm{CO}$, and $\mathrm{NO}_{x}$.

\section{EXPERIMENTAL SETUP AND METHODOLOGY}

\section{Engine Setup}

An experiment was carried out with four-stroke, water-cooled, single-cylinder diesel engine. Engine specifications are given in table 1 . The tested engine is coupled with an electrical dynamometer with the capacity of $10 \mathrm{~kW}$. The engine operated by load conditions like $0 \%, 25 \%, 50 \%, 75 \%$, and $100 \%$. All experiments were conducted at a constant speed and compression ratio of $1500 \mathrm{rpm}$ and 17.5. In this experiment, the used engine fuel is diesel and $20 \%$ of mahua biodiesel blend with diesel (Kulkarni et al., 2011 \& Michael A Penny and Timothy J Jacobs, 2016). The experimental engine was run with and without modifications by using two techniques. One of the techniques is LHR, and another is LTC; the setup of both techniques is discussed below (Kulkarni et al., 2011). Engine speed is measured by using tachometer and temperatures of the engine like inlet air, exhaust gas, inlet, and outlet of water 
measured by using thermocouples. Exhaust gas smoke level is measured by using the smoke meter. Engine emissions like $\mathrm{CO}, \mathrm{HC}$, and $\mathrm{NO}_{\mathrm{x}}$ are measured by connecting exhaust gas analyzer.

Table 1. Specifications of tested engine.

\begin{tabular}{|c|c|}
\hline Description & Kirloskar \\
\hline Make & Single cylinder, direct injection, \\
\hline General details & $110 \mathrm{~mm}$ \\
\hline Stroke & $87.5 \mathrm{~mm}$ \\
\hline Bore & 17.5 \\
\hline Compression ratio & $1500 \mathrm{rpm}$ at $5.2 \mathrm{~kW}$ \\
\hline Rated speed and power & $210 \mathrm{bar}$ \\
\hline Injection Pressure & $24^{\circ} \mathrm{BTDC}$ \\
\hline Injection duration & \\
\hline
\end{tabular}

\section{Production of Mahua Oil Biodiesel}

In the present experimental engine, the used fuel is mahua oil. This mahua is a nonedible, fast-growth crop plant compared to other plants (Govinda Rao et al., 2018). Mahua oil has high viscosity, low heat value, etc. Production of biodiesel with mahua oil has done with two stages of processes, that is, esterification and transesterification. Esterification is done with acid catalyst $\mathrm{H} 2 \mathrm{SO} 4$ and methanol as shown figure 1 (Geos et al., 2017). After that, transesterification is done with catalyst $\mathrm{KOH}$ and methanol as shown in figure 2 (Modi et al., 2017).

Table 2 shows the properties of the fuel. And also, in this experiment, the tested fuel is B20 and ethanol 5\% blend is used.

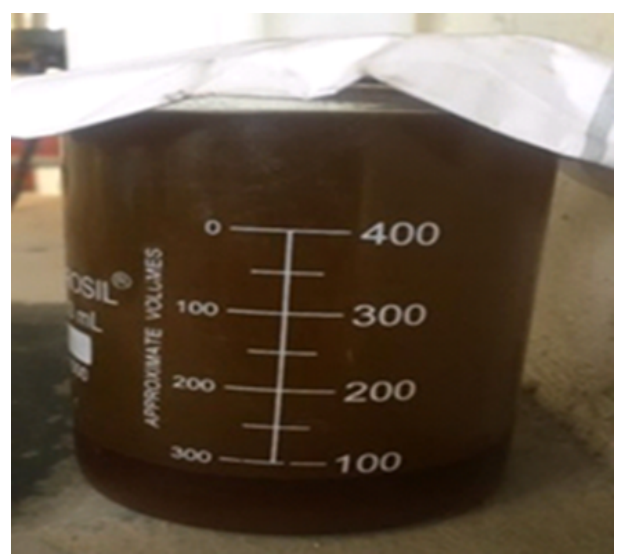

Figure 1. Esterification.

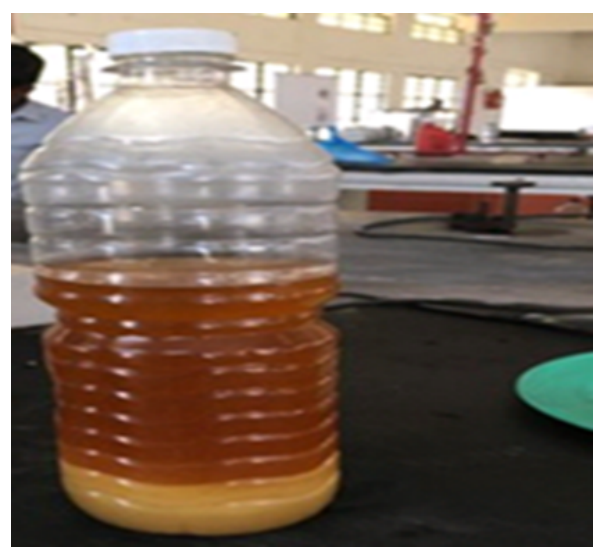

Figure 2. Transesterification. 
Table 2. Properties of Mahua biodiesel.

\begin{tabular}{|l|c|c|c|c|c|c|}
\hline Property & Unit & Mahua Oil & MOME & Diesel & D80/B20 & D75/B20/E5 \\
\hline Density & $\mathbf{K g} / \mathbf{m}^{\mathbf{3}}$ & 960 & 880 & 850 & 860 & 869 \\
\hline $\begin{array}{l}\text { Kinematic } \\
\text { Viscosity }\end{array}$ & $\mathbf{c S t}$ & 24.58 & 3.98 & 3.52 & 3.62 & 3.49 \\
\hline Flashpoint & ${ }^{\mathbf{o}} \mathbf{C}$ & 232 & 208 & 49 & 80 & 77 \\
\hline Calorific Value & $\mathbf{M J} / \mathbf{k g}$ & 36 & 37 & 42 & 38 & 40 \\
\hline Cetane Number & - & 45 & 47 & 53 & 51.2 & 51 \\
\hline
\end{tabular}

\section{Setup of LHR}

LHR has done the ceramic coating of engine parts including top surfaces of the piston, cylinder head, and valves with a thickness of 300 microns by using the plasma spray method. This modification of the engine is done with alumina (A12O3) as a low heat rejection material. It is one of the famous thermal barrier materials (Ramalingam et al., 2018). Because of ceramic coating, the bond coat was done with NiAlCr with a thickness of 200 microns for making a strong joint of ceramic materials in the engine parts. Figure 3 shows the cases before and after coating of piston crown. Table 3 shows the properties of Alumina.

Table 3. Properties of Ceramic Material.

\begin{tabular}{|c|c|c|}
\hline Parameters & Units & \\
\hline Chemical formula & & $\mathrm{Al}_{2} \mathrm{O}_{3}$ (Aluminum Oxide) \\
\hline thermal conductivity & $\mathrm{W} / \mathrm{mK}$ & 20 to 30 \\
\hline Hardness & $\mathrm{Gpa}$ & 15 to 19 \\
\hline density & $\mathrm{g} / \mathrm{cm}^{3}$ & 3.75 to 3.95 \\
\hline Melting point & ${ }^{\circ} \mathrm{C}$ & 2,072 \\
\hline Boiling point & ${ }^{\circ} \mathrm{C}$ & 2,977 \\
\hline
\end{tabular}
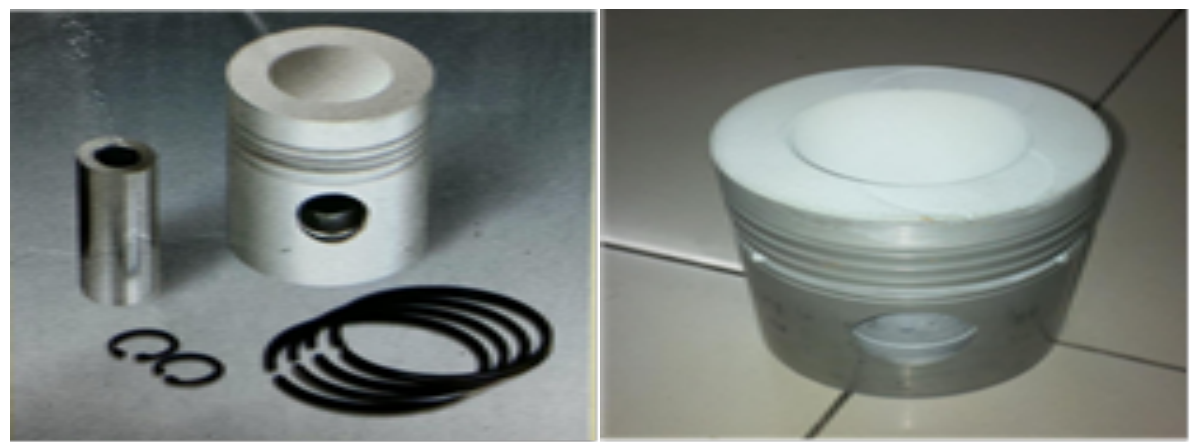

Figure 3. Before and after coating of the piston crown. 


\section{Setup of LTC}

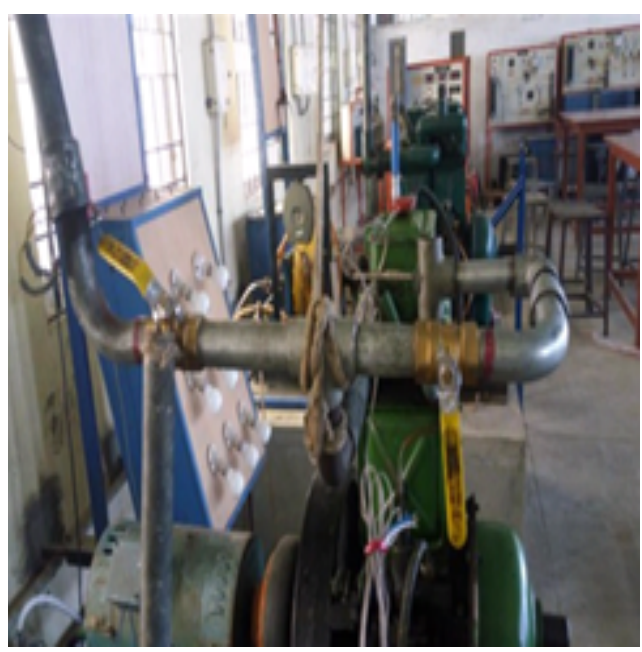

Figure 4. EGR setup.

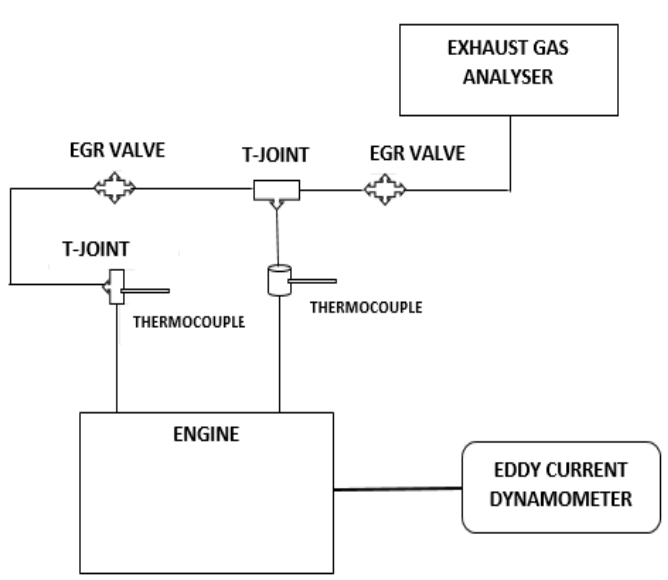

Figure 5. EGR block diagram.

The engine is designed to run on the exhaust gas by inserting it into the intake manifold pipe by means of an EGR valve. During the recirculation of the exhaust gas (Kulkarni et al., 2011), the EGR control valves are used to regulate the amount of exhaust allowed back into the combustion chamber. Figures 4 and 5 show the EGR setup and block diagram.

\section{Combination of LHR and EGR Setup}

One of the primary techniques is Low Heat Rejection (LHR) concept (or the so-called "Adiabatic" engine) applied in the experiment. In this case, improved efficiency can be achieved, but the disadvantage of the method is the increase in NOx emission by using optimal fuel B20 in the first phase of this study. Another technique is Exhaust Gas Recirculation (EGR) modes to mitigate NOx emission effectively by recirculating some exhaust gases like $0 \%$ to $20 \%$. But regarding this case, compared with LHR engine, $\mathrm{CO}$ and $\mathrm{HC}$ were increased due to low oxygen concentration. The above emission problems can be minimized by using LHR concepts combined with EGR discussed in this experiment. Also, 5\% ethanol and using simultaneously 15\%EGR were used to decrease the NOx. Only 5\% ethanol is used; the reason is ethanol's inability to get blended with diesel. The inlet temperature (IT) of the engine is regulated by E5 (5\% ethanol). So, in this paper, the best performance of diesel engine fueled biodiesel is given by adjusting the combination of using LHR and EGR with IT.

\section{Analysis of Uncertainty}

Table 4 provides the levels of accuracy of the measured values and the uncertainties of the observed parameters. To minimize measurement errors, six measurements have been observed, and only the average outcomes for analysis are presented (Banapurmath and Tewari, 2009). 
Table 4. The measured value of accuracy and uncertainties of parameters.

\begin{tabular}{|l|l|l|}
\hline S. No. & Parameters & Uncertainty \\
\hline $\mathbf{1}$ & Speed (rpm) & \pm 1 \\
\hline $\mathbf{2}$ & Load & \pm 0.1 \\
\hline $\mathbf{3}$ & Temperature $\left({ }^{\circ} \mathrm{C}\right)$ & \pm 1 \\
\hline $\mathbf{4}$ & Fuel Consumption $(\mathrm{g})$ & \pm 0.1 \\
\hline $\mathbf{5}$ & Hydrocarbon $(\mathrm{HC})$ & $\pm 1.5 \%$ \\
\hline $\mathbf{6}$ & Carbon monoxide (CO) & $\pm 2.3 \%$ \\
\hline $\mathbf{7}$ & Nitrogen Oxide (NOx) & $\pm 2.5 \%$ \\
\hline $\mathbf{8}$ & Smoke & $\pm 2 \%$ \\
\hline $\mathbf{9}$ & Brake Thermal Efficiency (BTE) & $\pm 1.2 \%$ \\
\hline
\end{tabular}

\section{RESULT AND DISCUSSIONS}

Performance and emission of the diesel engine are examined with and without modifications fueled by diesel, biodiesel (B20), and blend with ethanol 5\%. Modifications are that LHR and LTC are combined to be used to study the engine performance with using biodiesel (B20) blended with 5\% of ethanol to compare with standard and LHR engine. This section discussed the obtained results of the diesel engine's performance, combustion, and emission characteristics compared to different conditions of the engine.

\section{Impact on BTE}

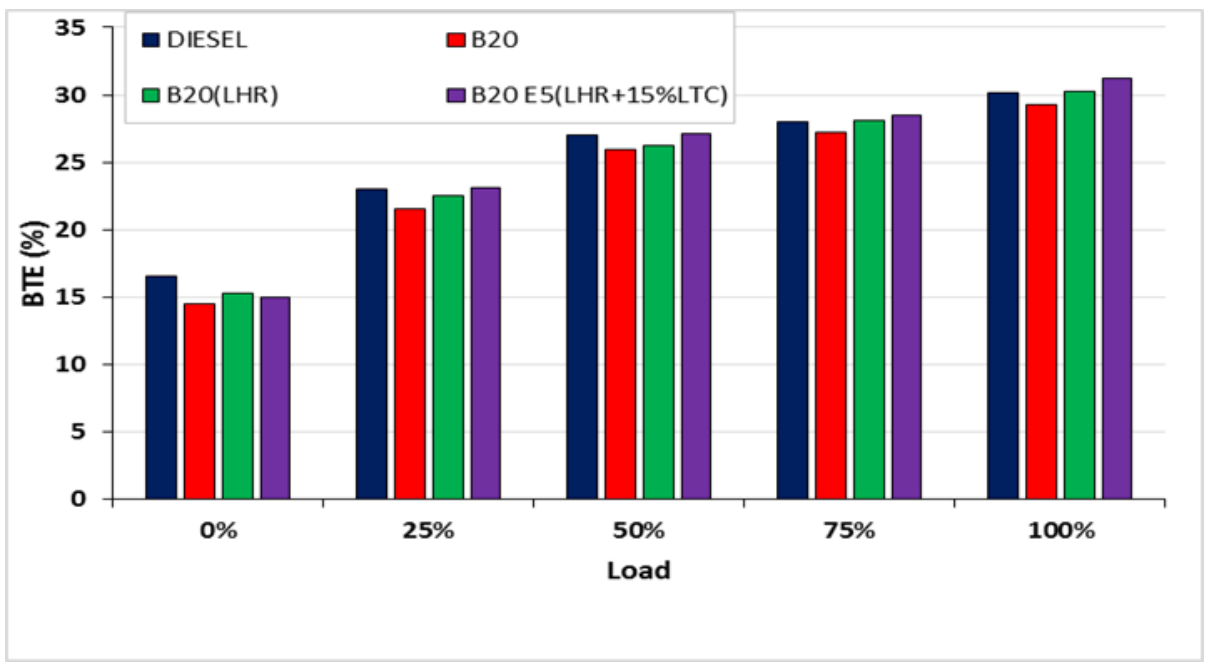

Figure 6. Brake Thermal Efficiency VS Load. 
Figure 6 illustrates the difference of brake thermal efficiency with different load conditions for various conditions of diesel engines. It shows that load increases with a slight increase in efficiency of the engine. Mainly, at full load condition, high BTE is obtained in B20E5 (LHR+15\%LTC) nearly to diesel operation of a conventional engine. Two modifications (LHR, LTC) are implemented at the same time in the diesel engine with optimum fuel (B20E5). Lower BTE has been seen in B20 due to less calorific value than diesel fuel (Kannan and Anand, 2011). LHR is used to reduce the heat loss and heat flux in the engine cylinder and improve engine efficiency (Xue et al., 2011). But it increases the NOx emission due to high-temperature combustion (Rakopoulos et al 2006). The LTC and 5\% ethanol in B20 are used to reduce the NOx emission by using the recirculation of exhaust gas of the engine. Compared to diesel fuel, BTE of B20 was 3.05\% less, and B20 (LHR) and B20E5 (LHR+15\%LTC) were improved by $0.3 \%$ and $3.48 \%$. From the figure, B20E5 (LHR+15\%LTC) shows a better BTE than others.

\section{Impact on BSEC}

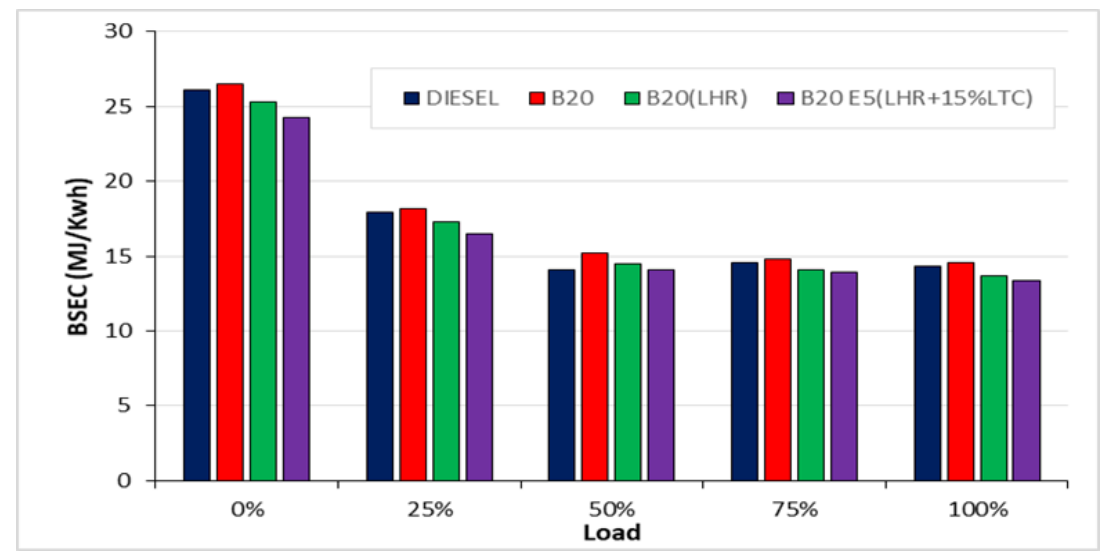

Figure 7. Brake Specific Energy Consumption VS Load.

Figure 7 displays the fluctuating of brake specific energy consumption (BSEC) from minimum to maximum various type of load conditions of a diesel engine fueled diesel and biodiesel blend. It observed that BSEC decreased with an increase in load. Overall, BSEC noticed that the maximum in B20 is $26.5 \mathrm{MJ} / \mathrm{Kwh}$ at $0 \%$ load, and the minimum in B20E5 (LHR+15\%LTC) is $13.4 \mathrm{MJ} / \mathrm{Kwh}$ at 100\% load conditions (Vamsi Krishna et al., 2018). BSEC of the engine was more in B20 compared to others. Because biodiesel has a lower calorific value, higher density, and viscosity than the diesel fuel, the energy content of biodiesel is lower than that of fossil fuel at the same power. Particularly, at $100 \%$ load condition, it shows less BSEC than other percentages of load in all conditions of the engine (Muthukumaran et al., 2018). Compared to diesel fuel, B20 was 2.09\% high, and B20 (LHR) and B20E5 (LHR+15\%LTC) were $4.19 \%$ and $6.29 \%$ less than what was revealed in full load conditions (Ramadhas et al., 2004). It seems that B20E5 (LHR+15\%LTC) gave satisfactory BSEC due to implementing the LHR and LTC methods at a time. Meanwhile, low BSEC shows improved engine efficiency.

\section{Impact on EGT}

Figure 8 displays the variation of exhaust gas temperature (EGT) from minimum to maximum various type of load conditions of a diesel engine fueled diesel and biodiesel blend. It is observed that the highest EGT was obtained in B20LHR, and the lowest EGT in diesel fuel at all load conditions. Particularly, LHR engine with biodiesel was found higher EGT compared to conventional diesel engines due to delay burning of biodiesel. The maximum EGT obtained was $328^{\circ} \mathrm{C}, 364^{\circ} \mathrm{C}, 319^{\circ} \mathrm{C}$, and $296^{\circ} \mathrm{C}$ For B20E5 (LHR+15\%LTC), B20LHR, B20, and diesel, respectively, 
at peak load. Among these, a reasonable EGT was found in B20E5 (LHR+15\%LTC) due to both LHR and LTC that were implemented in the engine and also 5\% ethanol blended in biodiesel (Banapurmath, and Tewari, 2009). The biodiesel's properties like higher viscosity, lower cetane number, and volatility led to a more prevailing diffusion combustion phase than that for diesel. The EGT was responsible for getting more BTE and meanwhile $\mathrm{NO}_{\mathrm{x}}$ emission (Xue et al., 2011).

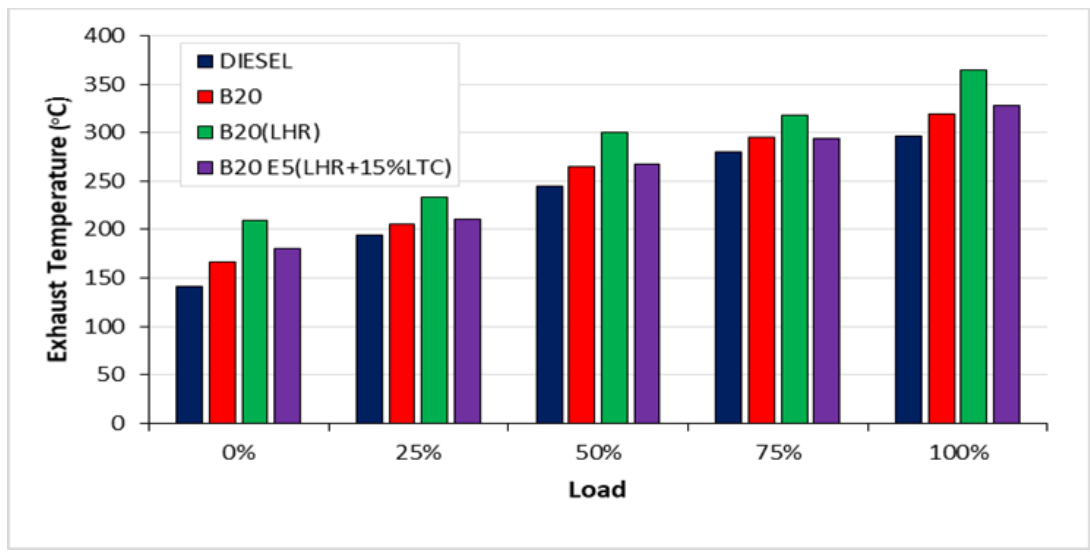

Figure 8. Exhaust Gas Temperature VS Load.

\section{Impact on In-Cylinder Pressure}

Figure 9 shows the in-cylinder pressure concerning the crank angle for different conditions of the engine at $100 \%$ load. It is observed that the peak pressure for diesel was 70.5 bar, for B20, 67.52bar, for B20LHR, 69.8bar, and for B20E5 (LHR+15\%LTC), 70.1bar at 10oCA ATDC (Ramadhas et al., 2004). From these outcomes, diesel peak pressure was near to B20E5 (LHR+15\%LTC) because of using two modifications at a time for biodiesel blend. The peak pressure was increased due to the raising of heat release, shorter combustion duration, and longer ignition delay. Generally, mahua oil biodiesel has a low cetane number compared to diesel fuel (Govinda Rao et al., 2018). The B20 was found to lower peak pressure compare to others due to low calorific value and high viscosity. But B20E5 (LHR+15\%LTC) has shown reasonable peak pressure compared to diesel fuel.

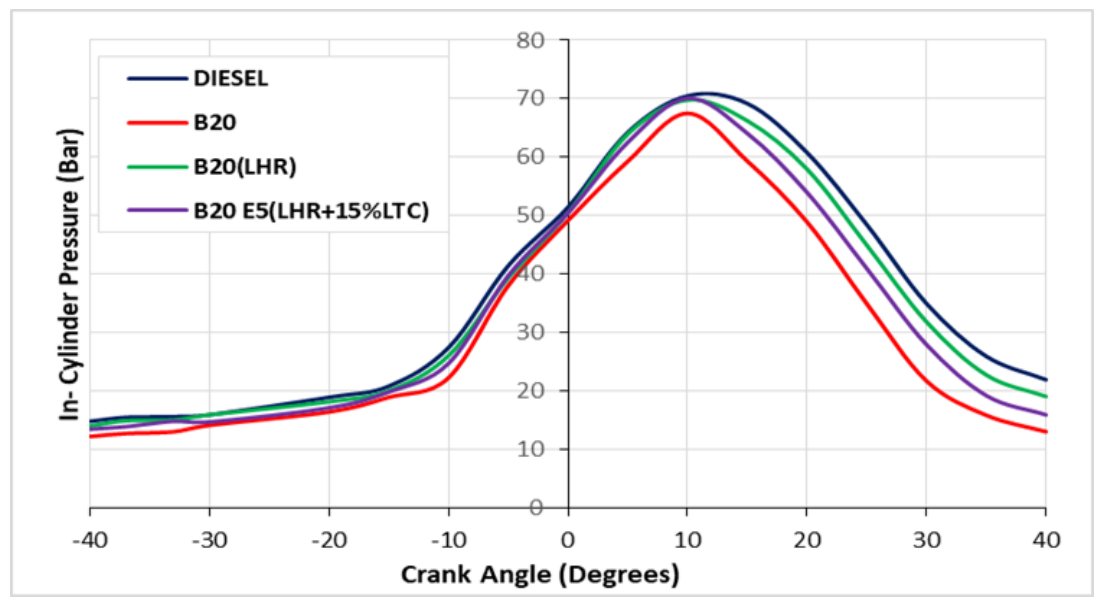

Figure 9. In-Cylinder Pressure Vs Crank Angles. 


\section{Impact on Heat Release}

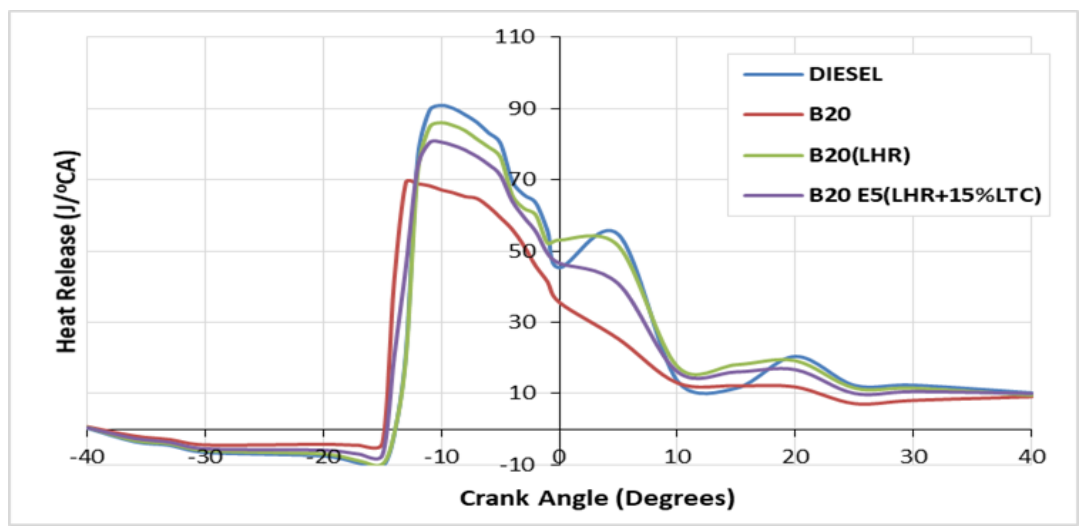

Figure 10. Heat release VS Crank Angles.

Figure 10 shows heat release concerning the crank angle for different conditions of the diesel engine at $100 \%$ load. At the beginning of combustion, a negative heat release is revealed, owing to the delay in the vaporization of the gas collected during the delay in ignition (Senthil et al., 2015 \& Michael A Penny and Timothy J Jacobs, 2016).

The heat release has become positive after the start of combustion. Overall, diesel fuel $\left(90.9 \mathrm{~J} /{ }^{\circ} \mathrm{CA}\right)$ has higher heat release than others (B20, B20LHR and B20E5 (LHR+15\%LTC)). The least heat release obtained in the B20 blend is due to less calorific value and cetane number of biodiesel. Peak heat release of diesel, B20LHR, and B20E5 $(\mathrm{LHR}+15 \% \mathrm{LTC})$ was attained in the same crank angle $\left(10^{\circ} \mathrm{CA} \mathrm{BTDC}\right)$ expect $\mathrm{B} 20\left(69.36 \mathrm{~J} /{ }^{\circ} \mathrm{CA}\right.$ at $\left.13^{\circ} \mathrm{CA} \mathrm{BTDC}\right)$. B20LHR (86.04 J/ $/{ }^{\circ} \mathrm{CA}$ ) was the second-highest compared to the remaining conditions (Geo et al., 2017). Because of implementing LHR engine to increase the performance of the diesel engine fueled biodiesel, it seems that reasonable heat release was predicted in $\mathrm{B} 20 \mathrm{E} 5(\mathrm{LHR}+15 \% \mathrm{LTC})\left(80.6 \mathrm{~J} /{ }^{\circ} \mathrm{CA}\right)$ for applied two modifications and $\mathrm{B} 20 \mathrm{blend}$ in $5 \%$ of ethanol. It controls the heat release of the engine during the combustion to reduce the $\mathrm{NO}_{\mathrm{x}}$ emissions. However, $15 \%$ of LTC was applied to decrease $\mathrm{NO}_{\mathrm{x}}$ emissions, and it increased the efficiency. Compared to diesel fuel, $23.69 \%$, $5.39 \%$, and $11.32 \%$ less heat release were achieved for B20, B20LHR, and B20E5 (LHR+15\%LTC).

\section{Impact on Ignition Delay}

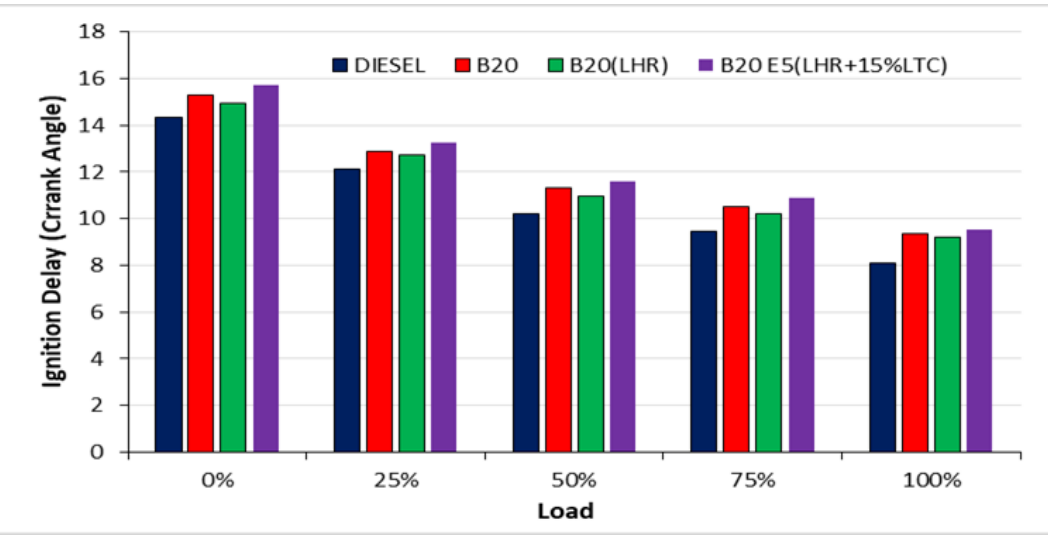

Figure 11. Ignition Delay VS Load. 
Figure 11 shows the variation of ignition delay (ID) about different load conditions of a diesel engine fueled diesel and biodiesel blend. From this graph, when the load increases, and the ignition delay gradually reduces, it can be anticipated to compare four-engine conditions with different load conditions and comparable variation in the crank angle. The highest ignition delay was found to be $15.72^{\circ} \mathrm{CA}$ at $0 \%$ load in $\mathrm{B} 20 \mathrm{E} 5$ (LHR+15\% LTC), and the minimum was $8.1^{\circ} \mathrm{CA}$ at $100 \%$ load in diesel fuel (Vinay kumar et al., 2012). Between $0 \%$ and $100 \%$ load conditions, the graph shows $25 \%$ to $75 \%$ load conditions, and changes in ignition delay are nearly much nearer to it. Due to particular load conditions from $25 \%$ to $75 \%$, it is evident that the variation in engine load is more or less equal to the required values (Randazzo Mario, and Sodre Jose, 2011). While comparing the ignition delay (diesel, B20, B20 (LHR), and B20E5 (LHR+15\% LTC)), the highest variation in diesel fuel was $43.55 \%$ from no load to full load. The rise in ignition delay with mahua oil biodiesel (B20) is due to the poor volatility and high viscosity, resulting in slow vaporization and blending.

\section{HC Emission}

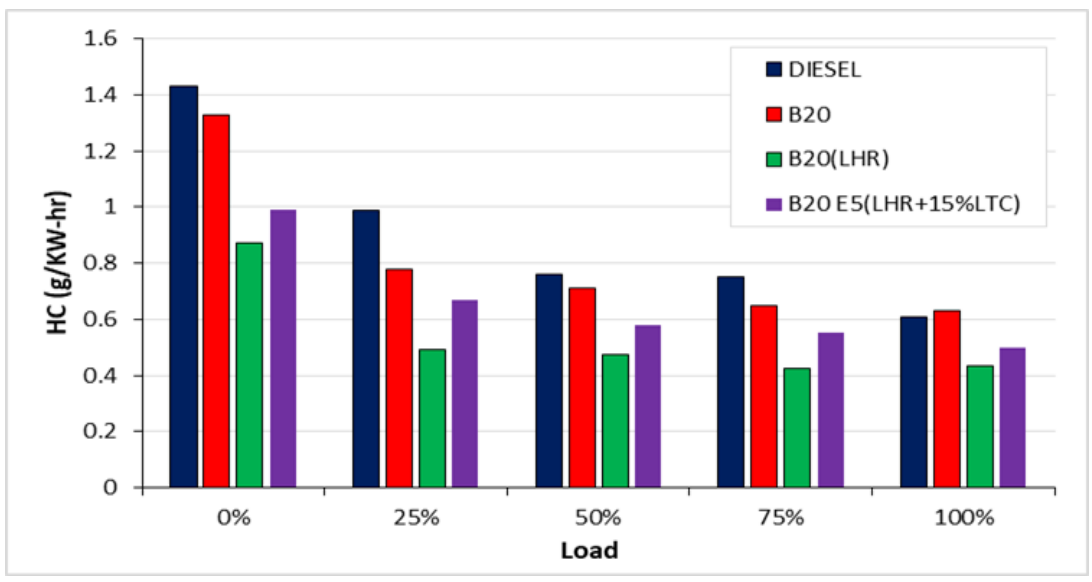

Figure 12. HC Emission VS Load.

$\mathrm{HC}$ emissions occur more due to the incomplete combustion of fuel. Commonly, it is a serious issue of diesel with lower load conditions (Govinda Rao et al., 2018). Figure 12 shows the variation of hydrocarbon (HC) emission with different load conditions for diesel, B20, B20 (LHR), and B20E5 (LHR+15\% LTC). Maximum HC emission levels were found in diesel compared to B20, B20 (LHR), and B20E5 (LHR+15\% LTC), while load increases were decreased with $\mathrm{HC}$ emissions. At full load, the $\mathrm{HC}$ concentration of B20 increased by $3.27 \%$ and decreased by $29.28 \%, 18.36 \%$ for B20 (LHR), B20E5 (LHR+15 \% LTC) compared to diesel fuel. Mahua oil biodiesel has an oxygen content that increases the combustion temperature and reduces $\mathrm{HC}$ emissions (Michael A Penny and Timothy J Jacobs, 2016). It seems that lowest HC emission was shown in the B20 (LHR) in all load due to heat losses to coolant, and the outside was reduced by ceramic coating in engine parts, leading to increases in the temperature of combustion (Senthil et al., 2015). However, the B20E5 (LHR+15\% LTC) was noticed, where a significant amount of $\mathrm{HC}$ emission was produced at all load conditions. Because simultaneously using LHR and $15 \%$ LTC is used to reduce $\mathrm{HC}$ emission, B20E5 (LHR+15 \% LTC) is 16.27\% higher than B20 (LHR) because of the use of 15\%LTC and 5\% ethanol in B20. Both LTC and ethanol will increase the level of $\mathrm{HC}$ emissions, but a sufficient amount will only be used in this study to decrease $\mathrm{NO}_{x}$ (C Srinidhi et al., 2019). 


\section{CO Emissions}

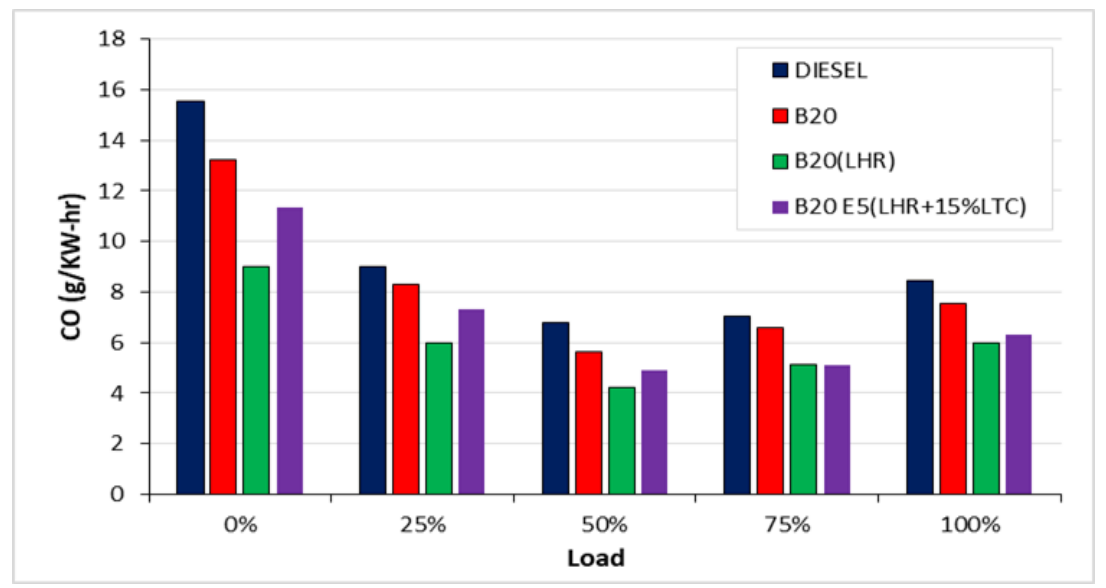

Figure 13. CO Emission VS Load.

$\mathrm{CO}$ emissions depend on the fuel properties and combustion characteristics of the diesel engine (Senthil et al., 2015). Figure 13 illustrates the variation of carbon monoxide (CO) emission with different load conditions for diesel, B20, B20 (LHR), and B20E5 (LHR+15 \% LTC). Here, also the same trend (Banapurmath and Tewari, 2009) of HC emissions due to both $\mathrm{HC}$ and $\mathrm{CO}$ emissions is generated due to incomplete combustion of fuel. Overall, the lowest $\mathrm{CO}$ emissions in all loads were noted in B20 (LHR) compared to diesel, B20, and B20E5 (LHR+15 percent LTC) because the LHR engine raises the combustion temperature, while engine load increases are decreased with $\mathrm{CO}$ emissions (Ramadhas et al., 2004). Coemissions for B20, B20 (LHR), and B20E5 (LHR+15\%LTC) were decreased at $100 \%$ load relative to diesel fuel by $10.99 \%, 29.19 \%$ and $25.39 \%$ owing to oxygen content in biodiesel. Although the B20 (LHR) and B20E5 (LHR+15\% LTC) values are very close in the 75\% load, B20E5 (LHR+15\% LTC) achieved the acceptable $\mathrm{CO}$ emission level in all load conditions because of implementing the modification techniques like LHR and 15\% of LTC (Kulkarni et al., 2011).

\section{NO ${ }_{x}$ Emission}

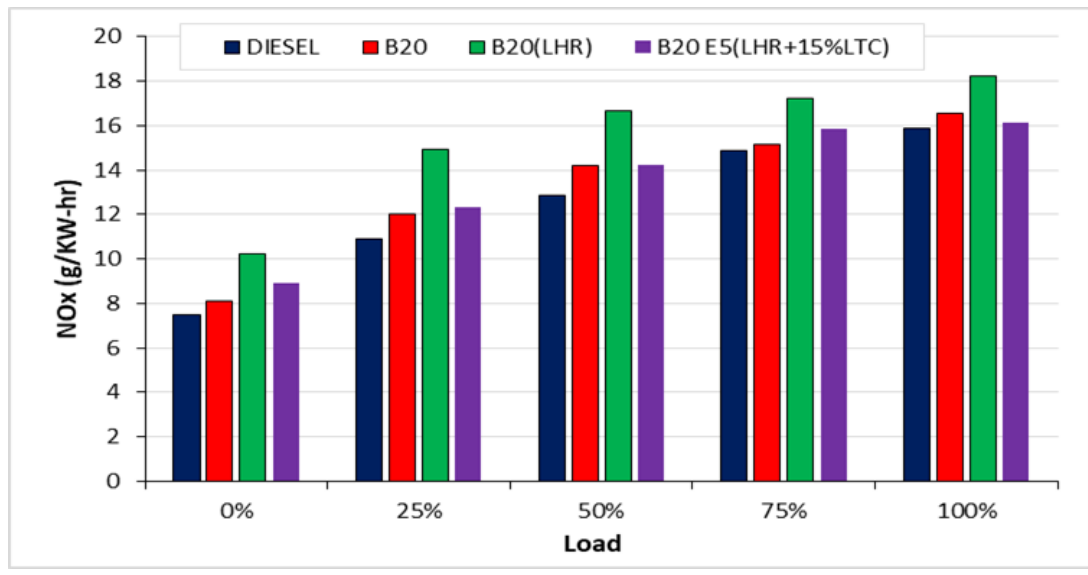

Figure 14. $\mathrm{NO}_{\mathrm{x}}$ Emission VS Load. 
Figure 14 illustrates the variation of $\mathrm{NO}_{\mathrm{x}}$ emission with different load conditions for diesel, B20, B20 (LHR), and B20E5 (LHR+15\% LTC). From the graph, when engine load increases with $\mathrm{NO}_{\mathrm{x}}$ emissions owing to the increase in combustion temperature, which indicates the temperature associated with the exhaust gas, it was revealed that, owing to the exhaust gas temperature of a coated engine fueled mahua oil biodiesel, $\mathrm{NO}_{\mathrm{x}}$ emission of B20 (LHR) was maximum at $100 \%$ load, which is $18.23 \mathrm{~g} / \mathrm{KW}$-hr (Vamsi Krishna et al., 2018). In the diesel fuel, a minimum $\mathrm{NO}_{\mathrm{x}}$ emission was achieved at a load of $0 \%$ which is $7.51 \mathrm{~g} / \mathrm{KW}-\mathrm{hr}$ compared to different load and fuel conditions. $\mathrm{NO}_{\mathrm{x}}$ emissions for B20, B20 (LHR), and B20E5 (LHR+15\%LTC) were increased at $100 \%$ load relative to diesel fuel by $3.91 \%, 14.95 \%$, and $1.25 \%$ owing to high combustion temperature. In particular, B20 (LHR) shows a higher percentage of $\mathrm{NO}_{\mathrm{x}}$ emissions compared to others because B20 (LHR) has a high exhaust temperature due to the heat retention of the ceramic layer in the engine. And also, it seems that the difference between diesel fuel and B20E5 (LHR $+15 \%$ LTC) at $100 \%$ load condition was very small, which is $1.2 \%$ compared to others. Because the concept of LHR+LTC was introduced in the diesel engine and 5\% of ethanol was also blended in B20 (Rakopoulos et al., 2006), it leads to a reduction in the exhaust gas temperature and is ascribed to a reduction in the NOx emission with biodiesel.

\section{Smoke Emission}

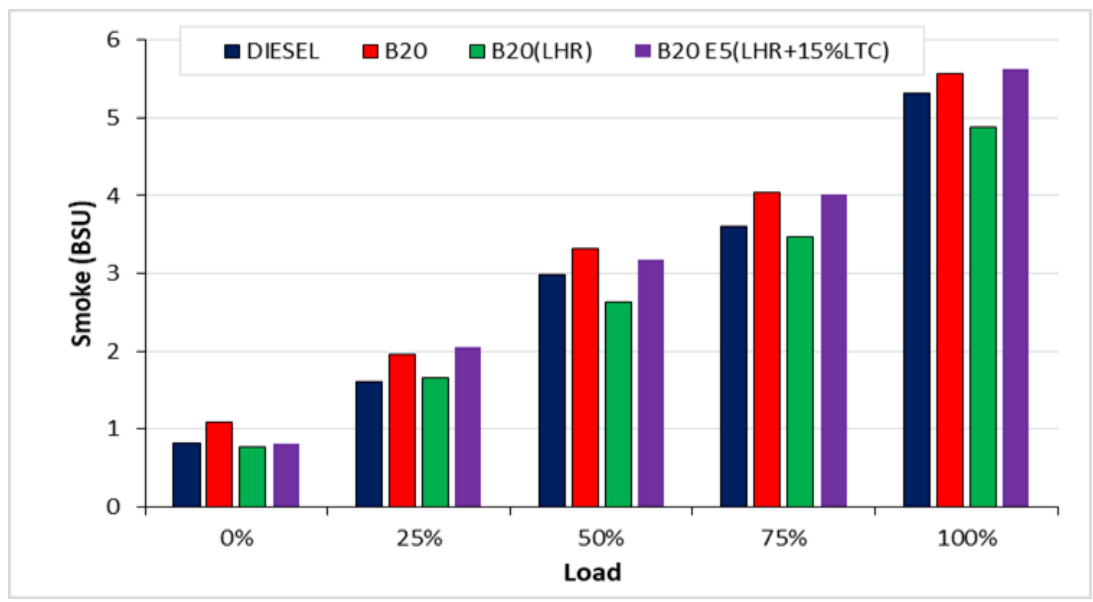

Figure 15. Smoke VS Load.

Smoke emissions were mainly dependent on air-fuel proportions and fuel characteristics (Govinda Rao et al., 2018). Figure 15 illustrates the variation of smoke emission with different load conditions for diesel, B20, B20 (LHR), and B20E5 (LHR+15 \% LTC). It is evident that, in any load condition, B20 (LHR) shows less smoke (0.77 BSU) compared to others. Because the covered engine creates an elevated temperature of combustion that reduces the smoke in the engine (Srinidhi Campli, 2017). Due to elevated viscosity, low cetane number, and calorific value in biodiesel, more smoke was observed in B20 (5.62 BSU). Smoke was generated, attributable to a longer ignition delay in the biodiesel (Govinda Rao et al., 2018). At $100 \%$ load, there were $4.84 \%$ and $5.89 \%$ more in B20 and B20E5 (LHR $+15 \%$ LTC) compared to diesel (Randazzo Mario and Sodre Jose, 2011). Likewise, the smoke concentration in B20 (LHR) was 8.02\% lower than that in diesel fuel though it was noted that B20E5 (LHR+15\% LTC) acquired a marginally higher variation in smoke for the implementation of LHR+LTC in the B20 engine mixed with $5 \%$ ethanol. 


\section{CONCLUSIONS}

The investigation of the present study was carried out by using a single-cylinder diesel engine with a combined effect of LHR and EGR fueled by diesel, mahua biodiesel (20\%), and ethanol (5\%). And also compared with conventional diesel, biodiesel engine, and LHR engine, the following onclusions are obtained through results and discussions.

- $\quad$ Compared to diesel fuel, B20E5 (LHR+15\% LTC) BTE is 3.48\% increased. BSEC is $6.29 \%$ decreased, EGT is $10.8 \%$ increased, $\mathrm{HC}$ is $18.36 \%$ decreased, $\mathrm{CO}$ is $25.39 \%$ decreased, $\mathrm{NO}_{\mathrm{x}}$ is $1.2 \%$ increased, and smoke is $5.89 \%$ increased.

- The increase in EGT and NOx emissions from LHR has decreased as a result of the implementation of the LTC.

- The findings showed an increase in BTE and also a decrease in the BSEC of the B20E5LHR+15\%LTC, in particular when compared to diesel. The combustion peak pressure and heat release rate were similar to those of the unmodified diesel engine and higher than those of the uncoated B20 engine.

- $\quad$ LHR reduced smoke density, and LTC increased smoke density. The net smoke density remained unchanged for the LHR+LTC engine fueled by B20 and was found to be lower than the diesel engine propelled by B20.

- $\quad$ Adding ethanol 5\% in B20 was used to get complete combustion along with combined effect LHR and LTC methods implemented in the diesel engine.

Finally, we observed modifications with both methods using at a time mean optimizing the fuel consumption and reducing the emission compared to other engines like B20, B20 (LHR).

\section{REFERENCES}

Kannan, G. R., \& Anand, R. 2011. Combustion characteristics of a diesel engine operating

on biodiesel-diesel-ethanol mixtures. Proceedings of the Institution of Mechanical Engineers Part A Journal of Power and Energy 225(A8):1076.

Xue, J., Grift, T.E., \& Hansen, A. C., 2011. Effect of biodiesel on engine performances and emissions. Renewable and Sustainable Energy Reviews. 15(2): 1098-1116.

Muthukumaran, N., Prasanna Raj Yadav, S., Saravanan, C. G., \& Sekar, T., 2018.

Synthesis of cracked Mahua oil using coal ash catalyst for diesel engine application. International Journal of Ambient Energy. 1-16.

Masjuki, H., Abdulmuin, M. Z., \& Sii, H. S., 1996. Investigations on preheated palm oil methyl esters in the diesel engine. Proceedings of the Institution of Mechanical Engineers Part A Journal of Power and Energy. 210:131- 138 .

Kulkarni, P. S., Sharanappa, G., Ramesh, M. R., Banapurmath, N. R., \& Khandal, S.V., 2011. Experimental investigations of a low heat rejection (LHR) engine powered with Mahua oil methyl ester (MOME) with exhaust gas recirculation (EGR). Biofuels.1-10.

Vamsi Krishna, K., Sastry, G. R. K., Murali Krishna, M. V. S., \& Deb Barma, J., 2018. Investigation on performance and emission characteristics of EGR coupled semi adiabatic diesel engine fuelled by DEE blended rubber seed biodiesel. Engineering Science and Technology, an International Journal. 21(1):122129. 
Geo, V. E., Sonthalia, A., Nagarajan, G., \& Nagalingam, B., 2017. Studies on performance, combustion and emission of a single cylinder diesel engine fuelled with rubber seed oil and its biodiesel along with ethanol as injected fuel. Fuel. 209:733-741.

Heywood JB, 2002. Internal combustion engine fundamentals. New York: McGraw-Hill.

Ramalingam, S., Rajendran, S., \& Ganesan, P., 2018. Performance improvement and exhaust emissions reduction in biodiesel operated diesel engine through the use of operating parameters and catalytic converter: A review. Renewable and Sustainable Energy Reviews.

81:3215-3222.

Govinda Rao, B., Datta Bharadwaz, Y., Virajitha, C., \& Dharma Rao, V., 2018. Effect of injection parameters on the performance and emission characteristics of a variable compression ratio diesel engine with plastic oil blends - An experimental study. Energy \& Environment. 29(4):492-510.

Modi, A. J., Gosai, D. C., \& Solanki, C. M., 2017. Experimental Study of Effect of EGR Rates on NOx and Smoke Emission of LHR Diesel Engine Fueled with Blends of Diesel and Neem Biodiesel. Journal of the Institution of Engineers (India): Series C. 99(2):181-195.

Senthil, R., Sivakumar, E., Silambarasan, R., \& Mohan, G., 2015. Performance and emission characteristics of a low heat rejection engine using Nerium biodiesel and its blends. International Journal of Ambient Energy. 38(2):186-192.

Vinay Kumar Domakonda, \& Ravi Kumar Puli, 2012. Application of Thermal Barrier Coatings in Diesel Engines: a Review. Energy and Power. 2(1):9-17.

Banapurmath, N. R., \& Tewari, P. G., 2009. Performance studies of a low heat rejection engine operated on non-volatile vegetable oils with exhaust gas recirculation. International Journal of Sustainable Engineering. 2(4):265-274.

Michael A Penny, \& Timothy J Jacobs, 2016. Efficiency improvements with low heat rejection concepts applied to diesel low temperature combustion. International J of Engine Research. 17(6):631-645.

Randazzo Mario L., \& Sodre Jose R., 2011. Exhaust emissions from a diesel powered vehicle fuelled by soybean bio-diesel blends (B3-B20) with ethanol as an additive (B20E2B20E5). Fuel. 90:98-103.

A.S., Ramadhas, S., Jayaraj, \& C., Muraleedharan, 2004. Use of vegetable oils as I.C engine fuels: a review. Renew. Energy. 29:727-742.

Rakopoulos, C. D., K. A., Antonopoulo, D. C., Rakopoulos, D. T., Hountalas, \& E. G., Giakoumis, 2006. Comparative Performance and Emissions Study of a Direct Injection Diesel Engine Using Blends of Diesel Fuel with Vegetable Oils or Biodiesels of Various Origins. Energy Conversion and Management. 47:32723287.

C., Srinidhi, A., Madhusudhan, S. V., Channapattana, 2019. Comparative analysis of exhaust gas recirculation and nanoparticles on the performance and emission of diesel engine fuelled with Neem biodiesel blend. International Journal of Ambient Energy. DOI: 10.1080/01430750.2019.1636876.

Srinidhi Campli, 2017. A Diesel Engine Performance Investigation fueled with Nickel oxide nano fuel-methyl ester. International Journal of Renewable Energy Research. 7(2): 676-681. 